\title{
Mineralogical and Physico-chemical Properties of Halloysite-bearing Slip Surface Material From a Landslide During the 2018 Eastern Iburi Earthquake, Hokkaido
}

\section{Jun Kameda ( $\nabla$ kameda@sci.hokudai.ac.jp)}

Department of Earth and Planetary Sciences, Faculty of Science, Hokkaido University, N10W8, Kita-ku, Sapporo, 060-0810 Japan

\section{Research article}

Keywords: 2018 Hokkaido Eastern Iburi earthquake, shallow landslide, liquefaction, halloysite

Posted Date: December 1st, 2020

DOl: https://doi.org/10.21203/rs.3.rs-113709/v1

License: (9) This work is licensed under a Creative Commons Attribution 4.0 International License.

Read Full License 


\section{Mineralogical and physico-chemical properties of}

2 halloysite-bearing slip surface material from a landslide

3 during the 2018 Eastern Iburi earthquake, Hokkaido

4 Jun Kameda ${ }^{1}$

5 Corresponding author

6 Email: kameda@sci.hokudai.ac.jp

7

8 (Institutional addresses)

91 Department of Earth and Planetary Sciences, Faculty of Science, Hokkaido University,

10 N10W8, Kita-ku, Sapporo, 060-0810 Japan

\section{Abstract}

13 Destructive landslides were triggered by the $6.7 \mathrm{M}_{\mathrm{w}}$ Eastern Iburi earthquake that struck

14 southern Hokkaido, Japan on 6 September 2018. Heavy rainfall on 4 September in addition to

15 intermittent rainfall around the Iburi Tobu area saturated and weakened altered volcanoclastic

16 soils containing halloysite minerals, making them susceptible to failure because of the

17 earthquake's strong ground motion. The landslides exhibited laminar flow behavior, with long

18 runouts along gentle hill slopes. This study investigated the mineralogical and physicochemical

19 properties of the halloysite-bearing slip surface material with the aim of understanding 
20 weakening and post-failure behaviors during the landslides. Halloysite in the slip surface had

21 irregular-to-hollow-spherical morphology with higher mesopore volumes than tubular

22 halloysite, which is related to a high capacity for water retention after rainfall. To reproduce

23 possible chemical changes in the slip surface during rainfall, the sample was immersed in

24 varying amounts of rainwater; solution $\mathrm{pH}$ increased and ionic strength decreased with

25 increasing water content. These findings, alongside electrophoretic analysis, suggest that

26 rainwater infiltration could have increased the absolute zeta potential value of the slip surface

27 material. It is suggested that rainfall before the earthquake enhanced the colloidal stability of

28 halloysite particles within the slip surface, owing to an increase in electrostatic repulsion. This

29 decreased the material's cohesive strength, which might have led to destabilization of the slope

30 during ground shaking generated by the earthquake, and subsequent high-mobility flow after

31 failure.

33 Keywords

342018 Hokkaido Eastern Iburi earthquake, shallow landslide, liquefaction, halloysite 


\section{Introduction}

The Eastern Iburi earthquake $\left(\mathrm{M}_{\mathrm{w}}=6.7\right)$ occurred at 3:07 AM (local time) on 6 September 2018 in southern Hokkaido, Japan (Fig. 1a). The resulting strong ground motion (with a maximum intensity of 7 on the Japan Meteorology Agency [JMA] intensity scale) caused hill slopes near the epicenter to fail suddenly. These slopes are widely covered by volcanic soils that originated from nearby volcanoes such as Tarumai, Eniwa, and Shikotsu (Yamada 1958; Katsui 1959; Furukawa and Nakagawa 2000). Around 6000 landslides occurred in the area (Yamagishi and Yamazaki 2018), with many of the recorded landslides being shallow and exhibiting features of liquefaction, such as long runouts of debris on relatively gentle slopes $\left(<\sim 30^{\circ}\right.$; Osanai et al. 2019; Kasai and Yamada 2019). Field surveys revealed that the basal part of the volcanic soils acted as the principal slip surface (Chigira et al. 2018; Kameda et al. 2019; Ito et al. 2020); these soils characteristically contain the mineral halloysite (Chigira et al. 2018; Kameda et al. 2019).

Halloysite is a typical alteration product in pyroclastic deposits, and occurs after allophane in the weathering sequence (Wada 1977, 1980; Parfitt et al. 1983). Halloysite exhibits various morphologies in nature; the most common form is elongated tubes, but spheroidal and platy halloysite has also been observed (Askenasy, 1973; Joussein et al., 2005). Halloysite often occurs on the slip surface of landslides in volcanic areas of Japan (Chigira and Yokoyama 2005; 
al. 2017). Spherical halloysite is most common in such cases (Smalley, 1980). In general, halloysite-bearing soils and deposits exhibit higher peak as well as residual friction angles than those that contain platy clay minerals, which suggests that they may be stable on steep slopes (Moon 2016). However, the material also exhibits high sensitivity (i.e., loss of strength by remolding), which possibly causes high mobility flows after failure (Moon 2016). Moon (2016)

61 also suggested the important effects of physico-chemical interactions between the clay surfaces and cations in pore water on the rheological properties of halloysite-bearing soils. Rheological experiments have demonstrated that the flow properties of halloysite suspensions depend on the solution chemistry ( $\mathrm{pH}$ and $\mathrm{NaCl}$ concentration), which modify the halloysite surface properties and influence the resulting association types of individual particles (Theng and Wells 1995). Recently, Kluger et al. (2017) observed halloysite with a unique morphology in a tephra layer involved in a flow slide, and suggested that weak interparticle interactions contributed to the high sensitivity of the material. These findings indicate that evaluation of the surface physico-chemical properties of the constituent halloysite mineral and their changes in response to contacting pore water is key to understanding the mechanism of landslide initiation, as well

71 as their runout behavior in volcanic areas. This study analyzed the mineralogical and physico-

72 chemical properties of the slip surface material from a landslide triggered by the Eastern Iburi 
73 earthquake, and used the results to discuss the possible weakening process of the material.

\section{Studied landslide}

Kameda et al. (2019) described the studied landslide in detail. The site is located in the Tomisato district of Atsuma town, southern Hokkaido (Figs 1a and b). The hill had a slope of $\sim 20^{\circ}$, dipping westward; the hill largely collapsed, and slid downward with a runout distance of $\sim 100 \mathrm{~m}$ (Fig. 1c). The collapsed slope was covered by clayey striated mud (Fig. 1d), which was often wet during field surveys. The scarp of the landslide exhibited a stratigraphic sequence of pyroclastic deposits supplied from the Tarumai Volcano on a basement of Neogene marine beds: Ta-b (AD1667; Nakagawa et al. 2018), Ta-c (ca. 2.5 ka), and Ta-d (ca. 9 ka) deposits with two inter-bedded andosol layers (Fig. 1e). A clayey layer, several tens of centimeters thick and resembling the striated mud on the slope, was observed at the base of the scarp (i.e., the Ta-d layer). Based on field observations as well as the results of laboratory measurements, the clayey layer was found to act as a slip surface during the landslide. X-ray diffraction analysis revealed that the slip surface principally contained halloysite (Kameda et al. 2019). Surveys of several other locations indicated that many of the landslides around this area were triggered by the earthquake in a similar manner (Kameda et al. 2019). 


\section{Methods}

\subsection{X-ray diffraction (XRD) analysis}

Previous XRD analysis of the clay-size fraction of the slip surface material has revealed the occurrence of halloysite (Kameda et al. 2019). This study additionally conducted bulk XRD to quantify the halloysite content. The bulk powder sample, mixed with corundum (AX-5H, Hinomoto Kenmazai Co.) as an internal standard at a weight ratio of $4: 1$, was mounted on a

97 glass holder by side loading to minimize the development of a preferred alignment of the clay minerals. XRD patterns were recorded using a MAC Science MX-Labo with monochromatized $\mathrm{CuK} \alpha$ radiation at $40 \mathrm{kV}$ and $30 \mathrm{~mA}, 1^{\circ}$ divergence and anti-scattering slits, and a $0.15-\mathrm{mm}$ receiving slit in continuous scan mode at a rate of $1^{\circ} 2 \theta$ per minute. The weight contents of

101 crystalline phases such as halloysite and other minerals were determined using the reference

102 intensity ratio (RIR) (Hillier 2000). The RIR value $I / I_{\text {cor }}$ of the halloysite peak at $\sim 20^{\circ}$ $103(d=4.4 \AA)$, relative to corundum, was determined to be 0.225 from the measurement of a 50:50

104 mixture using a commercially available standard sample (Halloysite nanoclay, Sigma-Aldrich).

105 The standard halloysite was a synthetic powder with tubular morphology (50 $\mathrm{nm}$ outer diameter 106 and $15 \mathrm{~nm}$ inner diameter). In the following, the standard sample was not further purified before use. 


\subsection{Transmission electron microscopy (TEM) observation}

109 The morphological features of the halloysite-bearing slip surface material were observed by

110 TEM (JEM-2100F, Jeol). For TEM observation, the fine fraction of the sample was separated

111 by centrifugation, and dispersed on a holey carbon film.

3.3 Specific surface area and pore size distribution by $\mathbf{N}_{2}$ adsorption-desorption analysis The specific surface area and pore size distribution (PSD) of the samples were measured

115 using an automated sorption analyser (Autosorb, Quantachrome Instruments). Prior to 116 measurement, the samples were dried and degassed at $105^{\circ} \mathrm{C}$ for $15 \mathrm{~h}$ under vacuum. Nitrogen

117 adsorption-desorption assessed at $77 \mathrm{~K}$ provided isotherms for Brunauer-Emmett-Teller 118 (BET) analysis to determine the surface areas. The adsorption isotherm was also provided for 119 PSD analysis based on the Barrett-Joyner-Halenda (BJH) method (Barrett et al. 1951). For 120 comparison, we also analyzed the standard samples of halloysite and allophane (Sekado-2,

121 Shinagawa General Co., Ltd.). The standard allophane was a purified sample collected from 122 Kitakami pumice, Iwate, Japan. The allophane particles has a hollow spherical morphology 123 with $\sim 5 \mathrm{~nm}$ outer diameter and $\sim 3 \mathrm{~nm}$ inner diameter (Brigattie et al. 2006). 


\subsection{Water adsorption-desorption measurement}

The adsorption and desorption of water were measured using an automated sorption analyser (N-VP, MicrotracBEL). Prior to measurement, the bulk powder sample was dried and degassed at $105{ }^{\circ} \mathrm{C}$ for $15 \mathrm{~h}$ under vacuum. The water adsorption-desorption isotherm was obtained at $25{ }^{\circ} \mathrm{C}$ for relative pressures, $P / P_{0}$, ranging from 0 to 0.9 .

\subsection{Immersion of the slip surface material in distilled water and rainwater}

131 during rainfall, samples were immersed in rainwater and distilled water (FUJIFILM Wako Pure

132 Chemicals Co.) at different solid/water weight ratios (S/W), and $\mathrm{pH}$ and electrical conductivity

133 (EC) measurements of the resulting solutions were taken after $24 \mathrm{~h}$. The rainwater was sampled

134 on 30 August 2020 at Atsuma town in the same season as when the disaster occurred. Before

135 the experiments, solid contaminants were removed from the rainwater by filtering it through a

$136 \quad 0.45 \mu \mathrm{m}$ filter attached to the tip of a syringe.

\subsection{Zeta potential and dynamic light scattering analysis}

138 For electrophoretic measurement, samples were centrifuged to separate the $>2 \mu$ m clay

139 fraction. Samples were then dialyzed using distilled water until the conductivity of the outside

140 solution became $\sim 2.0 \mu \mathrm{S} / \mathrm{cm}$. The electrophoretic mobility $\mu$ of the sample was measured

141 using a Zetasizer Nano (Malvern), and the zeta potential $\zeta$ was obtained as follows based on 
142 the Smoluchowski relationship (Smoluchowski 1921):

$143 \mu=\frac{\varepsilon_{0} \varepsilon \zeta}{\eta},(1)$

144 where $\varepsilon_{0}$ is the vacuum permittivity, $\varepsilon$ is the dielectric constant of water, and $\eta$ is the

145 viscosity of the solution. The $\mathrm{pH}$ of the solution was adjusted by adding $\mathrm{HCl}$ and $\mathrm{NaOH}(0.01$

$146 \mathrm{~N})$ solutions with background ionic strength of $10^{-2}, 10^{-3}$, and $10^{-4} \mathrm{M} \mathrm{NaCl}$.

147 The hydrodynamic diameter of the particles (spherical equivalent) was measured using the

148 same apparatus as that used for electrophoretic mobility measurement (Zetasizer Nano), which

149 used dynamic light scattering after $24 \mathrm{~h}$ of the sample being immersed in solutions of different

150 ionic strengths $\left(10^{-4}-0.5 \mathrm{M} \mathrm{NaCl}\right)$.

151

1524 Results

153 Figure 2 shows the XRD pattern of the slip surface material with a corundum internal

154 standard. The pattern shows peaks for halloysite, but for plagioclase and clinopyroxene. The

155 RIR method yielded halloysite, plagioclase, and clinopyroxene contents of $\sim 40 \%, \sim 4 \%$, and

$156 \sim 4 \%$, respectively, with the remainder ( $\sim 50 \%)$ being amorphous low-crystalline materials such

157 as volcanic glass.

158 The TEM observation revealed that halloysite in the slip surface was mostly irregularly

159 shaped, but some particles appeared as hollow spheres with a wall thickness of several tens of 
nanometers (Fig. 3). The particles often formed large aggregates several hundreds of

161 nanometers in diameter. Tubular halloysite was rarely observed. Wada and Mizota (1979) found

162 that halloysite in the Ta-d layer (i.e., strata identical to the slip surface) comprised particles

163 shaped like wood shavings, but this was not observed here. Therefore, the morphological

164 features of halloysite possibly depend on location, even within a given stratum.

165 Figure $4 \mathrm{a}$ shows the $\mathrm{N}_{2}$ adsorption-desorption isotherms of the three samples; Table 1

166 summarizes the specific surface area and total pore volume determined from these isotherms.

167 The total pore volumes, estimated from the amounts of adsorbed $\mathrm{N}_{2}$ at a relative pressure of

$168 P / P_{0}=0.99$, are almost the same for the three samples $\left(0.35-0.39 \mathrm{~m}^{3} / \mathrm{g}\right)$. The specific surface

169 areas of the standard halloysite and allophane are 49 and $285 \mathrm{~m}^{2} / \mathrm{g}$, respectively, consistent with

170 previous results for the same samples (Saeki et al. 2010; Em et al. 2020), whereas the slip

171 surface material exhibited an intermediate value between the two standard samples $\left(118 \mathrm{~m}^{2} / \mathrm{g}\right)$.

172 The standard halloysite showed a reversible Type II isotherm from the classification of The

173 International Union of Pure and Applied Chemistry (IUPAC) (Sing 1985), suggesting that the

174 sample contained predominantly macropores $(>50 \mathrm{~nm})$, which is also supported by the PSD

175 curve derived from the BJH method (Fig. 4b). The standard allophane exhibited a Type IV

176 isotherm with some hysteresis indicating the presence of mesopores (Iyoda et al. 2012). The

177 PSD indicates the occurrence of mesopores with a peak around 4-5 nm in size, possibly 
corresponding to the inter-particle and inter-microaggregate spaces of allophane particles

179 (Wang et al. 2020). Micropores $(<2 \mathrm{~nm})$ due to the crust of allophane particles may also have

180 contributed to the increased amounts of adsorbed $\mathrm{N}_{2}$ compared with the other samples (Wada

181 1989; Tomura et al. 1997). The adsorption isotherm of the slip surface material resembles that

182 of the standard halloysite, but shows a clear hysteresis loop indicating the presence of

183 mesopores. The PSD shows higher volumes of mesopores (ranging from $\sim 2$ to $40 \mathrm{~nm}$ ) than the

184 standard halloysite, possibly owing to the different morphologies of the two samples (i.e.,

185 tubular halloysite in the standard sample and hollow spheres in the slip surface sample).

186 Figure 5a shows water adsorption-desorption isotherms of the three samples. Allophane

187 showed the greatest water adsorbed with two step rises of the isotherm at $P / P_{0}=0-0.3$ and $0.6-$

1880.9 ; these are possibly attributable to capillary condensation of water at micropores and

189 mesopores, respectively (Tomura et al. 1997; Suzuki et al. 2001). Such a step-like rise was not

190 shown by the slip surface material or the standard halloysite. The adsorbed amounts of water

191 on the slip surface material were approximately twice as large as those of the standard halloysite,

192 possibly due to the presence of mesopores, as represented by a larger hysteresis loop. This

193 feature may also have contributed to the higher water retention capacity of the slip surface

194 material in comparison with the tubular halloysite.

195 Figure 6 shows the results of immersion tests. The $\mathrm{pH}$ of the rainwater increased as the 
$197=0.2$. In contrast, the EC of the solution decreased as the amount of water increased, from 60 $198 \mu \mathrm{S} / \mathrm{cm}$ at $\mathrm{S} / \mathrm{W}=0.65$ to $30 \mu \mathrm{S} / \mathrm{cm}$ at $\mathrm{S} / \mathrm{W}=0.2$. These values correspond to $\sim 5.0 \times 10^{-4}$ and $199 \sim 0.25 \times 10^{-4} \mathrm{M} \mathrm{NaCl}$, respectively. Using distilled water obtained almost similar results (Fig. $2006)$.

Figures 7 shows the results of electrophoretic analysis of the slip surface material. For 202 comparison, standard allophane and halloysite were also analyzed (Fig. 7a). The zeta potential of allophane increased from $-35 \mathrm{mV}$ at $\mathrm{pH}=\sim 12$ to $+30 \mathrm{mV}$ at $\mathrm{pH}=\sim 2$, with a point of zero 204 charge (PZC) at $\mathrm{pH}=\sim 6$. The zeta potential of the standard halloysite increased from $-45 \mathrm{mV}$ 205 at $\mathrm{pH}=\sim 10$ to $+10 \mathrm{mV}$ at $\mathrm{pH}=\sim 2$, with a $\mathrm{PZC}$ at $\mathrm{pH}=\sim 3$. These results are largely consistent 206 with the literature (Vergaro et al. 2010; Kawachi et al. 2013). The zeta potential of the slip 207 surface material largely behaved in a similar manner to the standard halloysite, but differed at 208 lower $\mathrm{pH}$. The reason for this discrepancy is uncertain, but could be due to the samples' differing 209 morphological features (as described above). We also examined the dependence of ionic 210 strength on the zeta potential of the slip surface material. Figure $7 \mathrm{~b}$ indicates that the zeta 211 potential decreased (an increase in absolute value) as ionic strength decreased from $10^{-2}$ to $10^{-4}$ 212 M particularly at $\mathrm{pH}>3.5$.

213 The hydrodynamic diameter of the particles was $\sim 1000 \mathrm{~nm}$ below $5.0 \times 10^{-4} \mathrm{M} \mathrm{NaCl}$ (Fig. 
214 8). It initially increased up to $3000 \mathrm{~nm}$ as ionic strength increased, then dropped to $2000 \mathrm{~nm}$

215 at $<0.05 \mathrm{M}$.

216

\section{Discussion}

218 The studied landslide was eventually triggered by the earthquake, but heavy rainfall due to

219 a typhoon and intermittent rainfall over several weeks before the earthquake saturated and

220 weakened the volcanic soil on the slope. Halloysite in the slip surface had an irregular-to-

221 hollow-spherical morphology with higher mesopore volumes than the tubular halloysite, which

222 may have contributed to its high water retention capacity, and thus the soil containing such

223 halloysite may have been wet for a long period after rainfall. The immersion test results suggest

224 that successive rainwater infiltration of the slip surface could have modified the pore water

225 chemistry, with $\mathrm{pH}$ increasing and ionic strength decreasing (Fig. 6). The zeta potential

226 measurements (Fig. 7) suggest that both these changes enhanced the stability of colloidal

227 halloysite particles as the absolute values of zeta potential increased. This implies a qualitative

228 decrease in the soil's cohesive strength (Plaza et al. 2018).

229 Applying the classic theory of Derjaguin-Landau-Verwey-Overbeeck (DLVO theory) for

230 colloidal stability, I attempted to estimate the interparticle potential of the halloysite particles.

231 The potential energy can be obtained by the sum of the electrostatic double layer (i.e., repulsive 
232 energy $V^{\mathrm{EL}}$ ) and Lifshitz-van der Waals (attractive energy $V^{\mathrm{LW}}$ ) interactions as a function of

233 distance between the particles $s$ :

$234 \quad V_{T}=V^{E L}(s)+V^{L W}(s)$

235 For spherical particles, these energies can be expressed as follows (Duran et al. 1998;

236 Israeravili 2012):

237

$V^{E L}(s)=2 \pi \varepsilon_{0} \varepsilon a \zeta^{2} \ln (1+\exp (-\kappa s)),(3)$

$238 V^{L W}(s)=\frac{-A}{6}\left(\frac{2 a^{2}}{s(4 a+s)}+\frac{2 a^{2}}{(2 a+s)^{2}}+\ln \left(\frac{s(4 a+s)}{(2 a+s)^{2}}\right)\right)$

239 where $a$ is the particle radius, $A$ is the Hamaker constant, and $\kappa$ is the reciprocal of the

240 Debye length (double-layer thickness). Applying $a=1000 \mathrm{~nm}$ from the dynamic light

241 scattering experiment (Fig. 8) and $A=2.5 \times 10^{-20} \mathrm{~J}$ (a silicate surface typically shows $A=\sim$

$242(1-5) \times 10^{-20} \mathrm{~J}$; Lagaly 2006), the interparticle potentials (in $k T$ where $k$ is the Boltzmann

243 constant and $T$ is temperature in kelvin) can be plotted as in Figure 9.

244 The interparticle potential increased as ionic strength decreased at constant zeta potential

$245(-35 \mathrm{mV}$; Fig. 9a). For a constant ionic strength, the interparticle potential increased as the

246 zeta potential decreased (an increase in absolute value; Fig. 9b). These results also suggest

247 that increasing $\mathrm{pH}$ and decreasing ionic strength due to increasing rainwater infiltration

248 enhanced the interparticle potential, thereby causing a loss in cohesive strength of the

249 material. Kameda et al. (2019) reported that natural water content during a field survey was 
$\sim 150 \%$, which corresponds to a $\mathrm{S} / \mathrm{W}$ of $\sim 0.67$ in Figure 3 . The water content should, however,

251 vary depending on the weather conditions, and will be less during the dry season.

252 Interestingly, if the main ion species in the pore water are assumed to be $\mathrm{Na}^{+}$and $\mathrm{Cl}^{-}$, the $\mathrm{EC}$

253 corresponds to a concentration of $\sim 5.0 \times 10^{-4} \mathrm{M}$ (Figure 6), above which the particle diameter

254 increases quickly, owing to coagulation (Figure 8; i.e., the critical coagulation concentration;

255 Van Olphen 1977). This suggests that the cohesive strength of the materials increases quickly

256 if the water content decreases from the state described above. In this case, heavy rainfall due

257 to Typhoon Jebi (on 4 September) as well as intermittent rainfall over a period of several

258 weeks in the summer of 2018 likely saturated the slip surface. As discussed above, this might

259 have reduced its cohesive strength, and facilitated destabilization by coseismic ground motion

260 and high-mobility flow after failure.

261 Electrophoretic measurement also revealed that the $\mathrm{PZC}$ of allophane is at $\mathrm{pH}=\sim 6.0$ and

262 the absolute zeta potential value is much smaller than that of the slip surface material at

263 neutral pH (Fig. 7), suggesting that the cohesive strength of the upper strata containing

264 allophane is larger than those containing halloysite. This may be one reason why halloysite

265 has often been observed in the slip surfaces of the landslides in volcanic areas (Chigira and

266 Yokoyama 2005; Chigira at al. 2012; Nakano et al. 2013; Moon 2016; Kluger et al. 2017).

267 The alteration of volcaniclastic sediments first produces allophane, which is successively 
replaced by halloysite (Wada 1977; 1980; Parfitt et al. 1983), possibly due to dissolution-

269 recrystallization transformation processes (Inoue, 1996). Consequently, the main clay

270 component varies with depth within volcanic soil deposits. Compilation of the ages of

271 volcaniclastic deposits in Japan and New Zealand (Okada et al. 1986; Lowe 1986; Inoue

272 1996) indicates that halloysite starts to $\sim 10^{4}$ years after deposition, which is consistent with

273 the age of the studied strata ( $9 \mathrm{ka}$ for Ta-d). Therefore, progression of the weathering reaction

274 is likely a key process for the production of mechanically weak layers that can easily collapse

275 in volcanic areas, as observed in the present landslides.

276 Note that these inferences remain qualitative, and further work is necessary for more

277 quantitative discussion. For instance, rain water in Tomakomai city, $10 \mathrm{~km}$ away from Atsuma

278 town, does have $\mathrm{Na}^{+}$and $\mathrm{Cl}^{-}$as its main ions species, but their concentrations fluctuate

279 (Shibata and Sakuma 1994). The presence of other cation (such as $\mathrm{Ca}^{2+}, \mathrm{Mg}^{2+}$, or $\mathrm{K}^{+}$) and

280 anion (including $\mathrm{SO}_{4}{ }^{2-}$ and $\mathrm{NO}^{3-}$ ) species can modify the surface physico-chemical properties

281 of the halloysite particles. Rheological measurements of halloysite suspensions have

282 demonstrated that the yield stress generally increases with decreasing $\mathrm{pH}$ (Theng and Wells

283 1995). This can be interpreted as a decrease in interparticle potential at lower $\mathrm{pH}$ (Fig. 7).

284 However, the suspension's rheology shows complicated behavior depending on $\mathrm{NaCl}$

285 concentration as well as the morphology of the halloysite (Theng and Wells 1995). In-situ soil 
monitoring would provide precise information about the way the water's ionic composition

287 changes during rainfall. In addition, future work should consider the rheological properties of

288 halloysite-bearing soil under variable chemical conditions.

\section{Conclusions}

291 The mineralogical and physico-chemical properties of the slip surface material from a landslide

292 triggered by the 2018 Hokkaido Eastern Iburi earthquake were examined. This study reached

293 the following conclusions.

294 (1) TEM observation revealed that halloysite in the slip surface exhibited irregular and

295 occasionally spherical morphology. Halloysite tubes or particles with a wood shaving-like

296 shape, as documented in previous work, were not observed here.

297 (2) Halloysite in the slip surface has higher mesopore volumes than the standard tubular sample,

298 which may be related to a high capacity of water retention after rainfall.

299 (3) To simulate possible chemical changes in soils during rainfall, samples were immersed in

300 rainwater at different $\mathrm{S} / \mathrm{W}$ ratios. Increasing rainwater infiltration appeared to increase the

$301 \quad \mathrm{pH}$ and decrease the EC within the slip surface.

302 (4) Electrophoretic measurements showed that the zeta potential of the slip surface material

303 behaved similarly to a standard halloysite sample, but with differences at lower $\mathrm{pH}$. 
Generally, the absolute zeta potential values increased with increasing $\mathrm{pH}$ and decreasing solute concentration.

306 (5) Applying DLVO theory to the obtained zeta potentials derived the interparticle potential of halloysite. The potential increased with decreasing solute concentration and increasing

308 absolute zeta potential. These findings collectively suggest that rainwater saturation

309 enhanced the colloidal stability of halloysite particles, and resulted in the decrease in

310 cohesive strength of the material. These phsyico-chemical effects might also have affected

311 the rheological properties of the volcanic soil, and led to the eventual collapse and 312 downflow of debris triggered by seismic ground motion.

\section{Abbreviations}

315 PSD: Particle size distribution; EC: Electrical conductivity; S/W: Solid/water weight ratios

\section{Declarations}

\section{Availability of data and material}

319 The datasets supporting the conclusions of this article are included within the article (and its

320 additional file. 
323 The authors declare that they have no competing interest.

\section{Funding}

326 This work was supported by a JSPS Grant-in-Aid for Scientific Research (18H0129508).

\section{Authors' contributions}

329 JK designed the study, carried out the experimental study, analyzed the data and construct

330 manuscript.

\section{Acknowledgements}

333 I thank Shuhei Shimoda and Tatsuhiro Sigyo for technical assistance with the TEM observations

334 and water adsorption-desorption experiment. The JEM-2100F Jeol instrument is registered

335 with the Open Facility system and managed by the Global Facility Center, Creative Research

336 Institution, Hokkaido University.

\section{References}

339 Askenasy PE, Dixon JB, McKee TR (1973) Soil Sci Soc Am Proc 37: 799-803. 
340 Barrett EP, Joyner LG, Halenda PP (1951) The Determination of Pore Volume and Area 341 Distributions in Porous Substances. I. Computations from Nitrogen Isotherms. J Am Chem $342 \quad$ Soc $73: 373-380$.

343 Brigatti MF, Galan E, Theng B.K.G. (2006) Structures and mineralogy of clay minerals. in: F. 344 Bergaya B.K.G. Theng, G. Lagaly (Eds.), Handbook of Clay Science, Elsevier, Amsterdam, 345 pp. 19-86.

346 Chigira M, Yokoyama O (2005) Weathering profile of non-welded ignimbrite and the water 78:187-207.

Chigira M, Nakasuji A, Fujiwara S, Sakagami M (2012) Catastrophic Landslides of Pyroclastics Induced by the 2011 off the Pacific Coast of Tohoku Earthquake. pp 139-147 in: Japan, Springer.

Chigira M, Tajika J, Ishimaru S (2019) Landslides of pyroclastic fall deposits induced by the 2018 Eastern Iburi Earthquake with special reference to the weathering of pyroclastics. DPRI Annuals, 62: 348-356.

Duran JDG, Ontiveros A, Delgado AV, Gonzalez-Caballero F (1998) Kinetics and interfacial interactions in the adhesion of colloidal calcium carbonate to glass in a packedbed. Appl 
Em Y, Stoporev, A, Semenov A, Glotov A, Smirnova E, Villevald G, Vinokurov V, Manakov A, Lvov Y (2020) Methane hydrate formation in halloysite clay nanotubes. ACS Sustainable Chem Eng 8(21):7860-7868.

Furukawa R, Nakagawa M (2000) Geological Map of Tarumae volcano. Geological Survey of Japan.

364 Geographical Survey Institute, (2018a) https://maps.gsi.go.jp/index 3d.html?z=17\&lat=42.7503723926834\&lon=141.91060960 292816\&pxsize $=2048 \& 1$ s $=$ std $\%$ 7C20180906hokkaido_atsuma 0906 do\&blend $=0 \# \& c p x=$ $10.581 \& \mathrm{cpy}=-70.126 \& \mathrm{cpz}=35.866 \& \mathrm{cux}=0.077 \& \mathrm{cuy}=-$ $\underline{0.304 \& c u z}=0.950 \& \operatorname{ctx}=0.000 \& \operatorname{cty}=0.000 \& \operatorname{ctz}=0.000 \& \mathrm{a}=1 \& \mathrm{~b}=0 \& \mathrm{dd}=0$ https://maps.gsi.go.jp/\#12/42.770442/141.985660/\&base=std\&ls=std\%7C20180906hokk aido_atsuma $0906 \mathrm{do} \% 7$ Cexperimental anno\&blend $=0 \&$ disp $=111 \& 1 \mathrm{~cd}=20180906$ hokkai $\underline{\text { do atsuma } 0906 \mathrm{do} \& \mathrm{vs}=\mathrm{c} 1 \mathrm{j} 0 \mathrm{~h} 0 \mathrm{k} 010 \mathrm{u} 0 \mathrm{t} 0 \mathrm{z} 0 \mathrm{r} 0 \mathrm{~s} 0 \mathrm{~m} 0 \mathrm{f} 1 \& \mathrm{~d}=\mathrm{vl}}$ XRD: comparison of a Rietveld and a reference intensity ratio (RIR) method and the importance of sample preparation. Clay Minerals 35: 291-302. 
376 Inoue A (1996) Solution-mediated phase transformations of clay minerals. Journal of the Mineralogical Society of Japan 25: 189-197. https://doi.org/10.2465/gkk1952.25.189

378

Ito Y, Yamazaki S, Kurahashi T (2020) Geological features of landslides caused by the 2018 Hokkaido Eastern Iburi Earthquake in Japan. Geological Society, London, Special Publications 501: https://doi.org/10.1144/SP501-2019-122

Iyoda F, Hayashi S, Arakawa S, John B, Okamoto M, Hayashi H, Yuan G (2012) Synthesis and adsorption characteristics of hollow spherical allophane nano-particles. Appl Clay Sci 56:

$$
77-83 \text {. }
$$

Joussein E, Petit S, Churchman J, Theng B, Righ D, Delvaux B (2005) Halloysite clay minerals $\ddot{y}$ a review Clay Minerals 40: 383-426.

Kameda J, Kamiya H, Masumoto H, Morisaki T, Hiratsuka T, Inaoi C (2019) Fluidized landslides triggered by the liquefaction of subsurface volcanic deposits during the 2018 Iburi-Tobu earthquake, Hokkaido. Sci Rep 9:13119. https://doi.org/10.1038/s41598-019$\underline{48820-y}$

Kasai M, Yamada T (2019) Topographic effects on frequency-size distribution of landslides triggered by the Hokkaido Eastern Iburi Earthquake in 2018. Earth Planets Space 71:89 https://doi.org/10.1186/s40623-019-1069-8

Katsui Y (1959) On the Shikotsu pumice-fall deposit. Special reference to the activity just 
Kawachi T, Matsuura Y, Iyoda F, Arakawa S, Okamoto M (2013) Preparation and characterization of DNA/allophane composite hydrogels. Coll Surf B: Biointerfaces 112: $429-434$.

Kluger MO, Moon VG, Kreiter S, Lowe DJ, Churchman GJ, Hepp D A, Seibel D, Jorat ME, Mörz T (2017) A new attraction-detachment model for explaining flow sliding in clay-rich tephras. Geology 45(2):131-134.

401

Lagaly G (2006) Colloid clay science. In: Bergaya, F., Theng, B.K.G., Lagaly, G. (Eds.), Handbook of Clay Science. Elsevier, Amsterdam, pp. 247-260.

Lowe DJ (1986) Controls on the rates of weathering and clay mineral genesis in airfall tephras: A review and New Zealand case study. In: S. M. Colman and D. P. Dethier, (eds.), Rates of Chemical Weathering of Rocks and Minerals, Academic Press, pp. 265-330.

Moon V (2016) Halloysite behaving badly: geomechanics and slope behaviour of halloysiterich soils. Clay Miner 51:517-528.

Nakagawa M, Amma-Miyasaka M, Miura D, Uesawa S (2018) Tephrastratigraphy in Ishikari Lowland, Southwestern Hokkaido: Eruption history of the Shikotsu-Toya volcanic field. Jour Geol Soc Jpn 124: 473-489.

411 Nakano M, Chigira M, Choun-Sian L (2013) Landslides of pumice fall deposits induced by the 

Chiba, Japan.

Okada K, Ossaka J, Matsui K, Suzuki M (1986) On the factors influencing the weathering of tephras in various parts of Japan. Jour Mineral Soc Jpn 17: 25-33.

Osanai N, Yamada T, Hayashi S, Kastura S, Furuichi T, Yanai S, Murakami Y, Miyazaki T, Tanioka Y, Takiguchi S, Miyazaki M (2019) Characteristics of landslides caused by the 2018 Hokkaido Eastern Iburi Earthquake. Landslides 16: 1517-1528, https://doi.org/10.1007/s10346-019-01206-7

Parfitt RL, Russell M, Orbell GE (1983) Weathering sequence of soils from volcanic ash involving allophane and halloysite, New Zealand. Geoderma 29 (1):41-57.

Plaza I, Ontiveros-Ortega A, Calero J, Romero C (2018) A new approach to triggering mechanism of volcano landslides based on zeta potential and surface free energy balance. Geomorph 301: 1-9.

Saeki K, Sakai M, Wada S (2010) DNA adsorption on synthetic and natural allophanes. Appl Clay Sci 50: 493-497. Tomakomai. Jpn Jour Soil Sci J PIant Nutr 65: 313-320. 

603-619.

Smalley I, Ross CW, Whitton J (1980) Clays from New Zealand support the inactive particle theory of soil sensitivity. Nature 288: 576-577, doi: 10.1038 /288576a0. imogolite by hydration heat measurement using as heat exchange absorbents for lower temperature heat source and speedy drying desiccant. J Ceramic Soc Jpn 109(10): 874-881.

Smoluchowski MV (1921) Handbook of Electricity and Magnetism. Barth, Leipzig. 366. 99-106. adsorption property of various clays and related materials for applications to humidity selfcontrol materials. Clay Sci 10: 195-203. Cytocompatibility and uptake of halloysite clay nanotubes. Biomacromolecules 11(3): 820-826. 
Wada K, Mizota C (1979) The Clay Science Society of Japan, 42.

449 Wada K (1980) Soils with Variable Charge. New Zealand Society of Soil Science, Lower Hutt, 87.

WADA K (1989) Allophane and Imogolite, in Minerals in Soil Environments (2nd ed) Soil Science Society of America, SSSA Book Series, 1, pp 1051-1087.

Wang S, Du P, Yuan P, Liu Y, Song H, Zhou J, Deng L, Liu D (2020) Structural alterations of 454 https://doi.org/10.1016/j.geoderma.2020.114561

Yamada S (1958) Studies on the history of volcanic eruptions of alluvium epoch in Hokkaido on the basis of depositional features of the pyroclastics. Monog Ass Geol Collab Jpn 8.

\section{Figure legends}

463 Figure 1. Location and occurrence of the studied landslide. (a) Locations of the epicenter of the

464 Eastern Iburi earthquake (red cross) and the study area. (b) 3D view of the hills near Atsuma 465 after the earthquake (produced by data from the Geographical Survey Institute, 2018a). (c) 
466 Close-up photograph of the studied landslide (taken on 6 September 2018; Geographical Survey

467 Institute, 2018b). (d) Striated mud on the collapsed slope (modified after Kameda et al. 2019).

468 (e) Scarp measuring 2-3 $\mathrm{m}$ in height, which contains a stratigraphic sequence of volcanoclastic

469 deposits (modified after Kameda et al. 2019).

470

471 Figure 2. Bulk XRD pattern of the slip surface material with a corundum internal standard.

472

473 Figure 3. TEM micrograph of halloysite in the slip surface. The particle indicated by the arrow

474 is a hollow sphere.

475

476 Figure 4. Results of the $\mathrm{N}_{2}$ adsorption-desorption experiments. (a) $\mathrm{N}_{2}$ adsorption-desorption

477 isotherms for the slip surface material, halloysite, and allophane. (b) Pore size distribution

478 (PSD) curves obtained from BJH analysis.

479

480 Figure 5. Water adsorption-desorption isotherms at $25^{\circ} \mathrm{C}$ for the slip surface material,

481 halloysite, and allophane.

482

483 Figure 6. Results of immersion tests. Changes in $\mathrm{pH}$ and electrical conductivity after sample 
484 immersion for $24 \mathrm{~h}$ in rainwater or distilled water (DW) at different solid/water weight ratios.

486 Figure 7. Results of electrophoretic analysis. (a) Zeta potentials with respect to $\mathrm{pH}$. Results for standard halloysite and allophane samples are included for comparison. (b) Zeta potentials with respect to $\mathrm{pH}$ at different solute concentrations. Error bars denote the range of three repeated measurements.

Figure 8 . Hydrodynamic diameter of particles $(\mathrm{nm})$. The diameter was measured by dynamic

492 light scattering as a function of solute concentration. Error bars denote the range of three repeated measurements.

494

495 Figure 9. Interparticle potential (in $k T$ ) based on DLVO theory. (a) The zeta potential was set at $496-35 \mathrm{mV}$. (b) The solute concentration was set as $5.0 \times 10^{-4} \mathrm{M}$.

499 Table 1. Specific surface area and total pore volume of the slip surface material, standard 500 halloysite, and allophane 


\section{Figures}
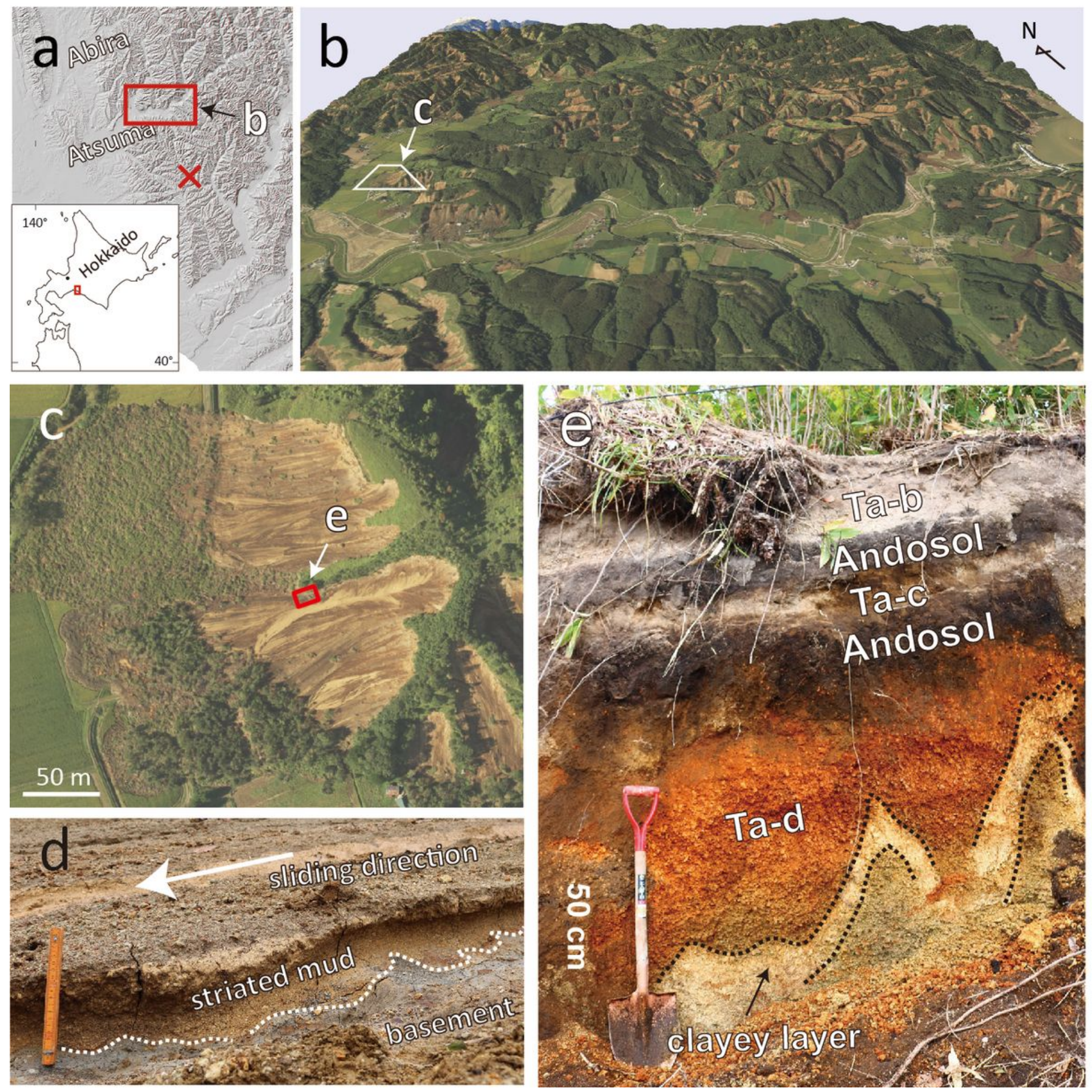

\section{Figure 1}

Location and occurrence of the studied landslide. (a) Locations of the epicenter of the Eastern Iburi earthquake (red cross) and the study area. (b) 3D view of the hills near Atsuma after the earthquake (produced by data from the Geographical Survey Institute, 2018a). (c) Close-up photograph of the studied landslide (taken on 6 September 2018; Geographical Survey Institute, 2018b). (d) Striated mud on the 
collapsed slope (modified after Kameda et al. 2019). (e) Scarp measuring 2-3 m in height, which contains a stratigraphic sequence of volcanoclastic deposits (modified after Kameda et al. 2019).

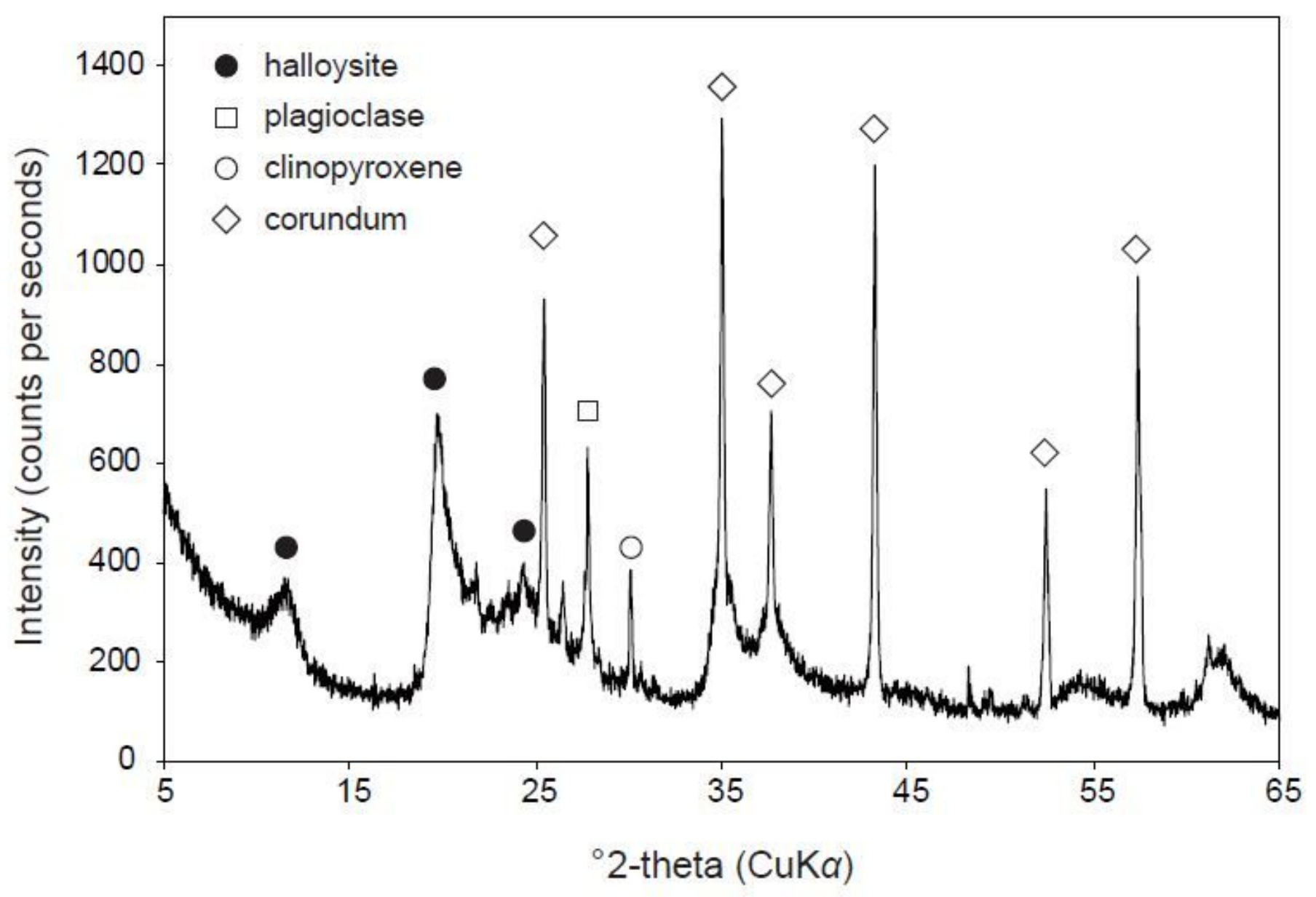

Figure 2

Bulk XRD pattern of the slip surface material with a corundum internal standard. 


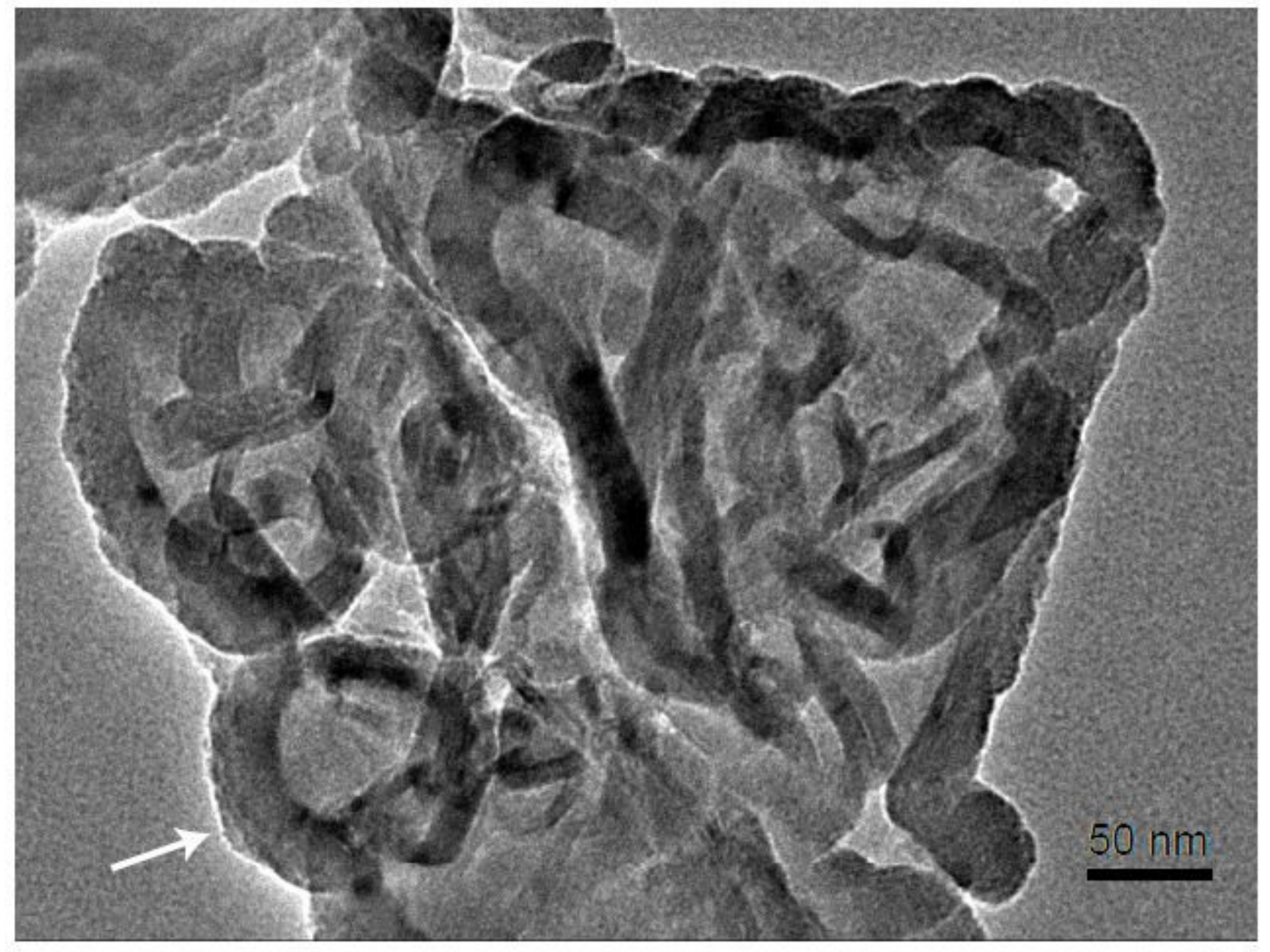

Figure 3

TEM micrograph of halloysite in the slip surface. The particle indicated by the arrow is a hollow sphere. 

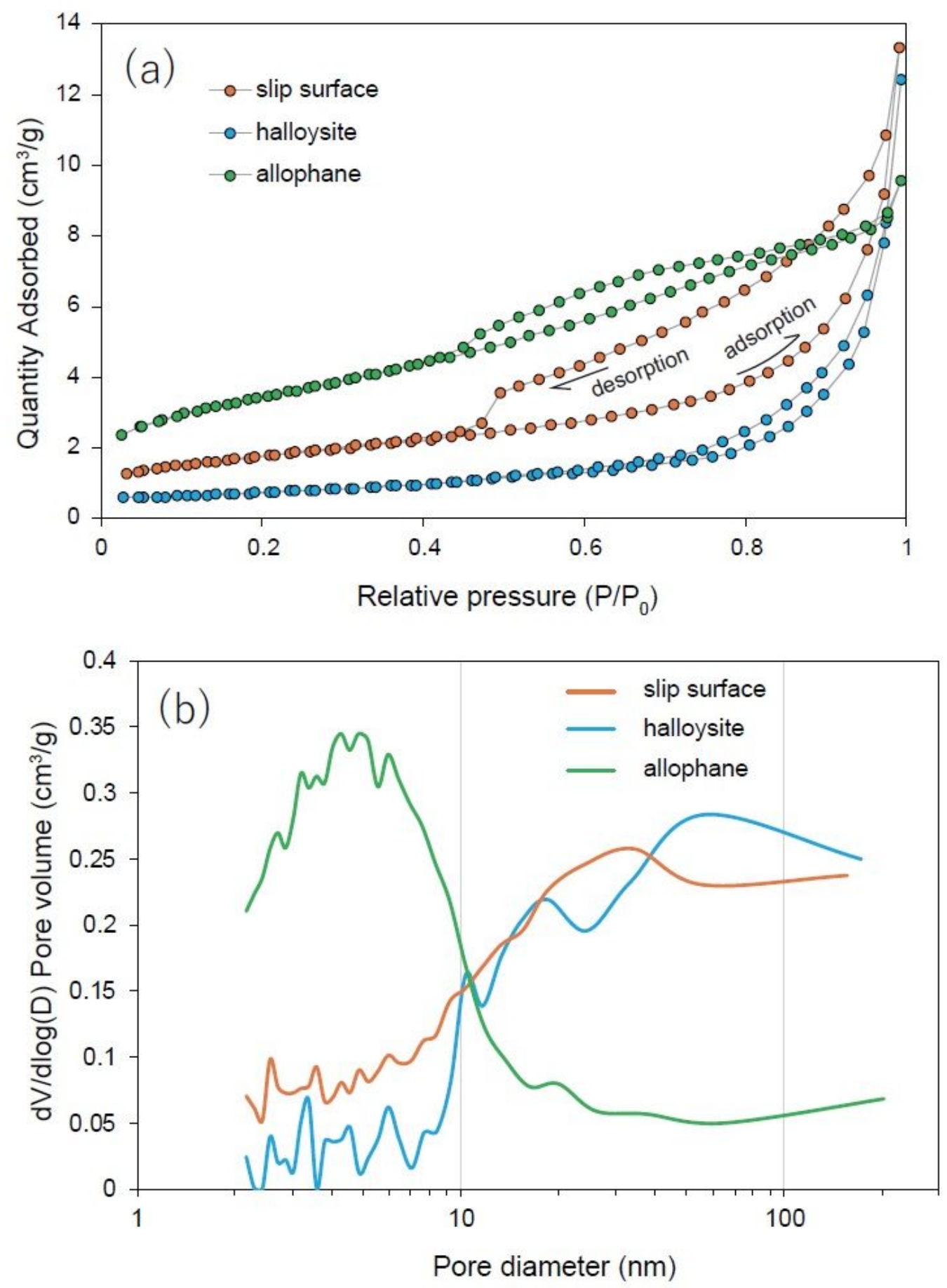

\section{Figure 4}

Results of the N2 adsorption-desorption experiments. (a) N2 adsorption-desorption isotherms for the slip surface material, halloysite, and allophane. (b) Pore size distribution (PSD) curves obtained from BJH analysis. 


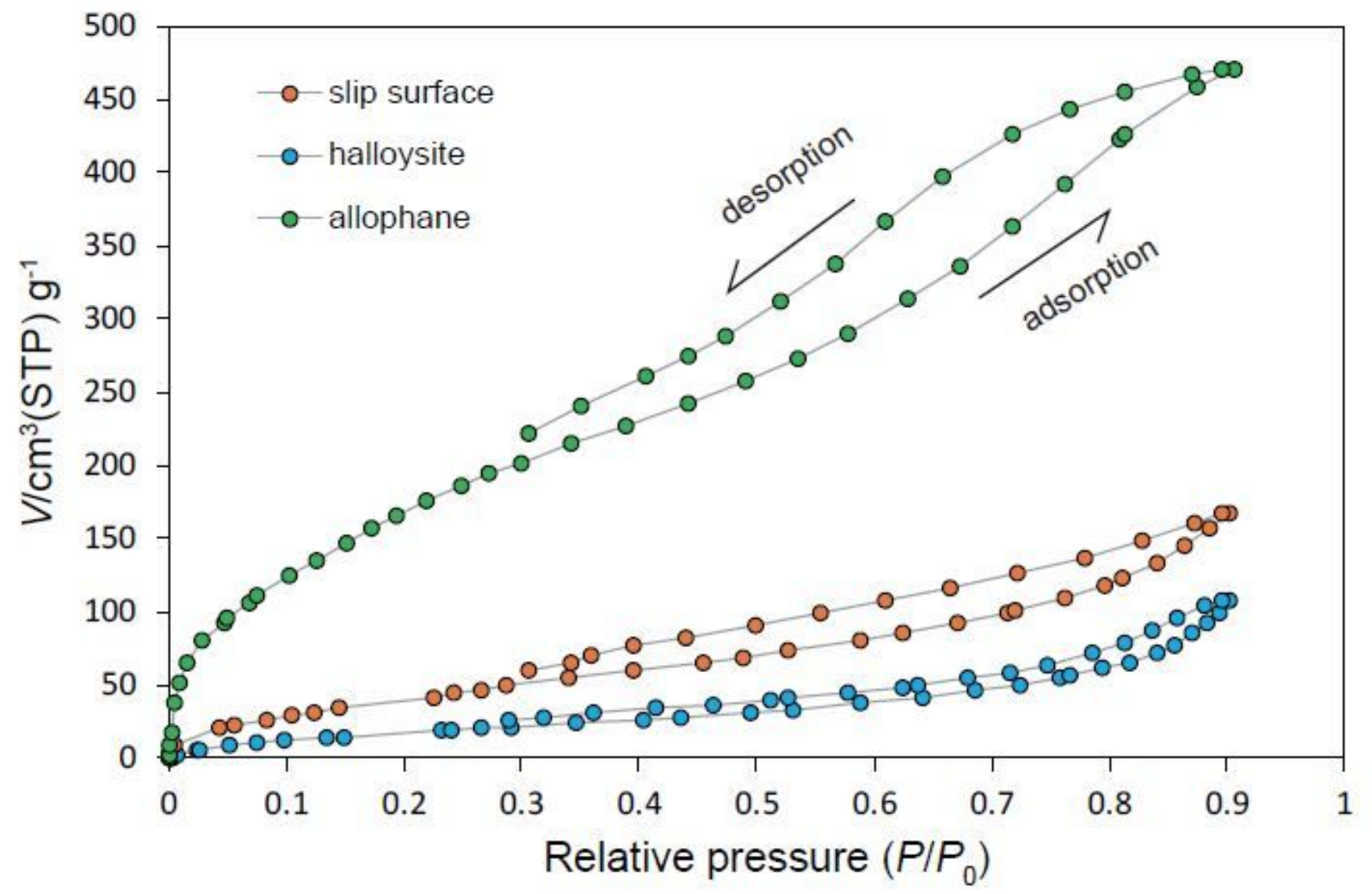

Figure 5

Water adsorption-desorption isotherms at $25^{\circ} \mathrm{C}$ for the slip surface material, halloysite, and allophane. 


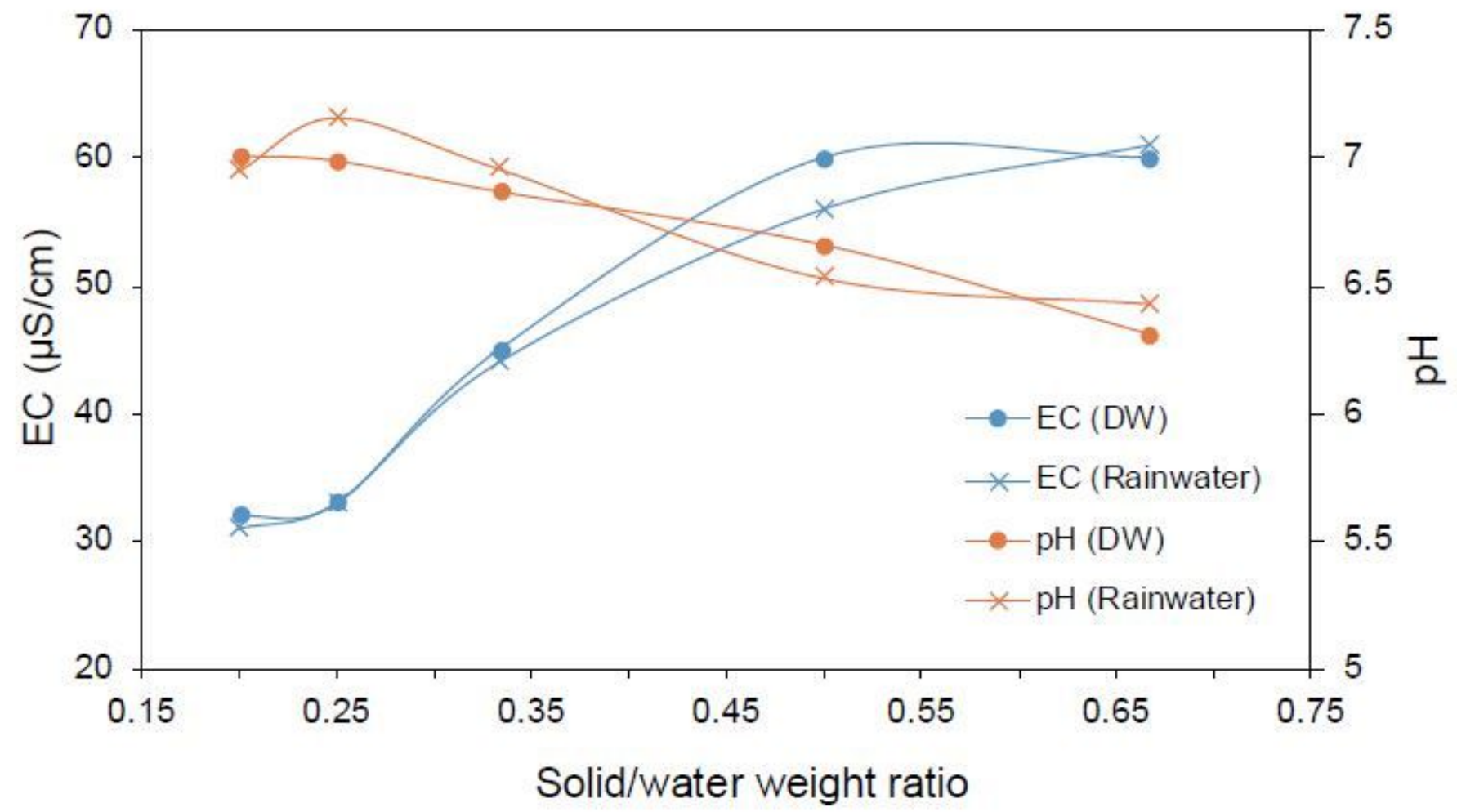

Figure 6

Results of immersion tests. Changes in $\mathrm{pH}$ and electrical conductivity after sample immersion for $24 \mathrm{~h}$ in rainwater or distilled water (DW) at different solid/water weight ratios. 

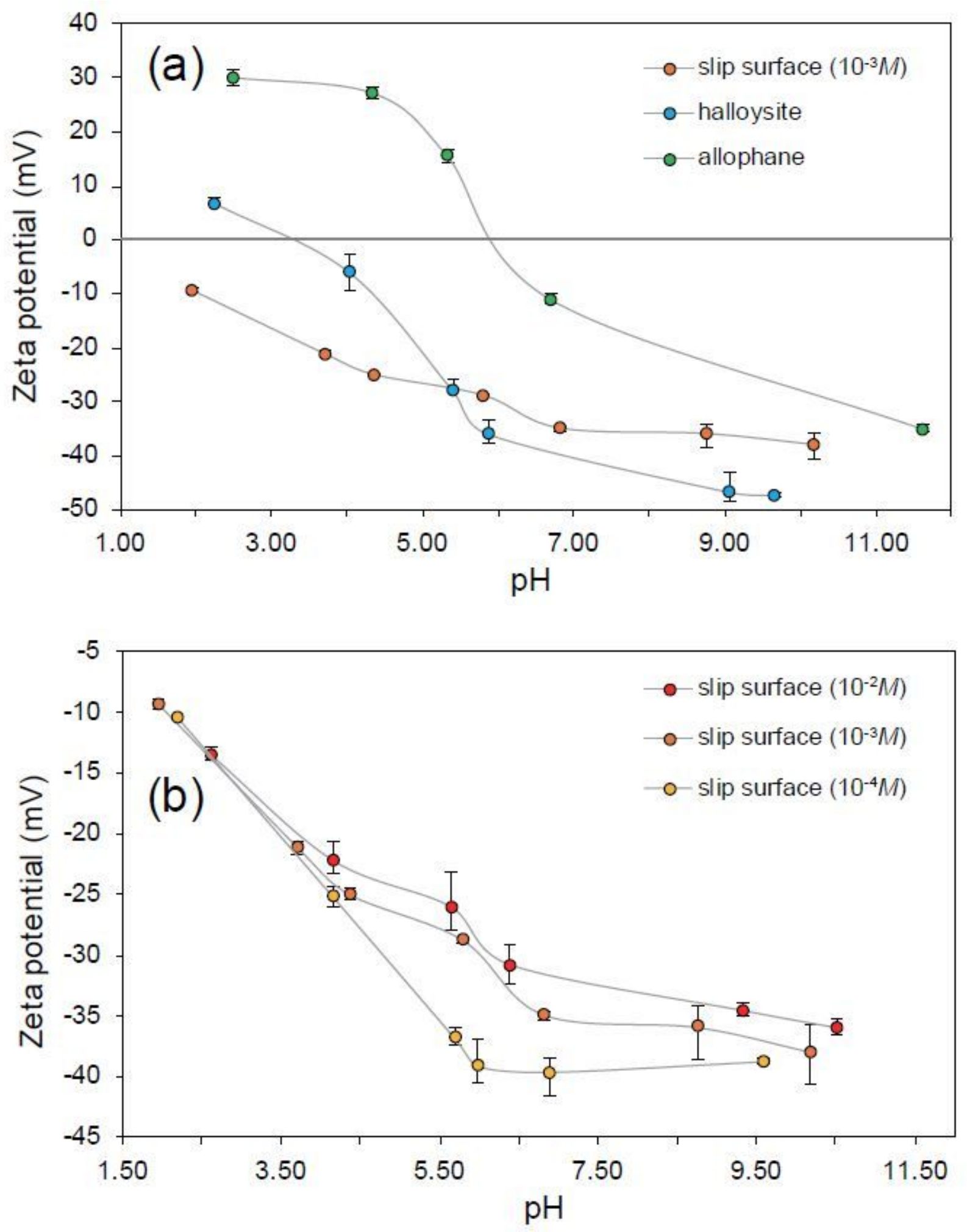

Figure 7

Results of electrophoretic analysis. (a) Zeta potentials with respect to $\mathrm{pH}$. Results for standard halloysite and allophane samples are included for comparison. (b) Zeta potentials with respect to $\mathrm{pH}$ at different solute concentrations. Error bars denote the range of three repeated measurements. 


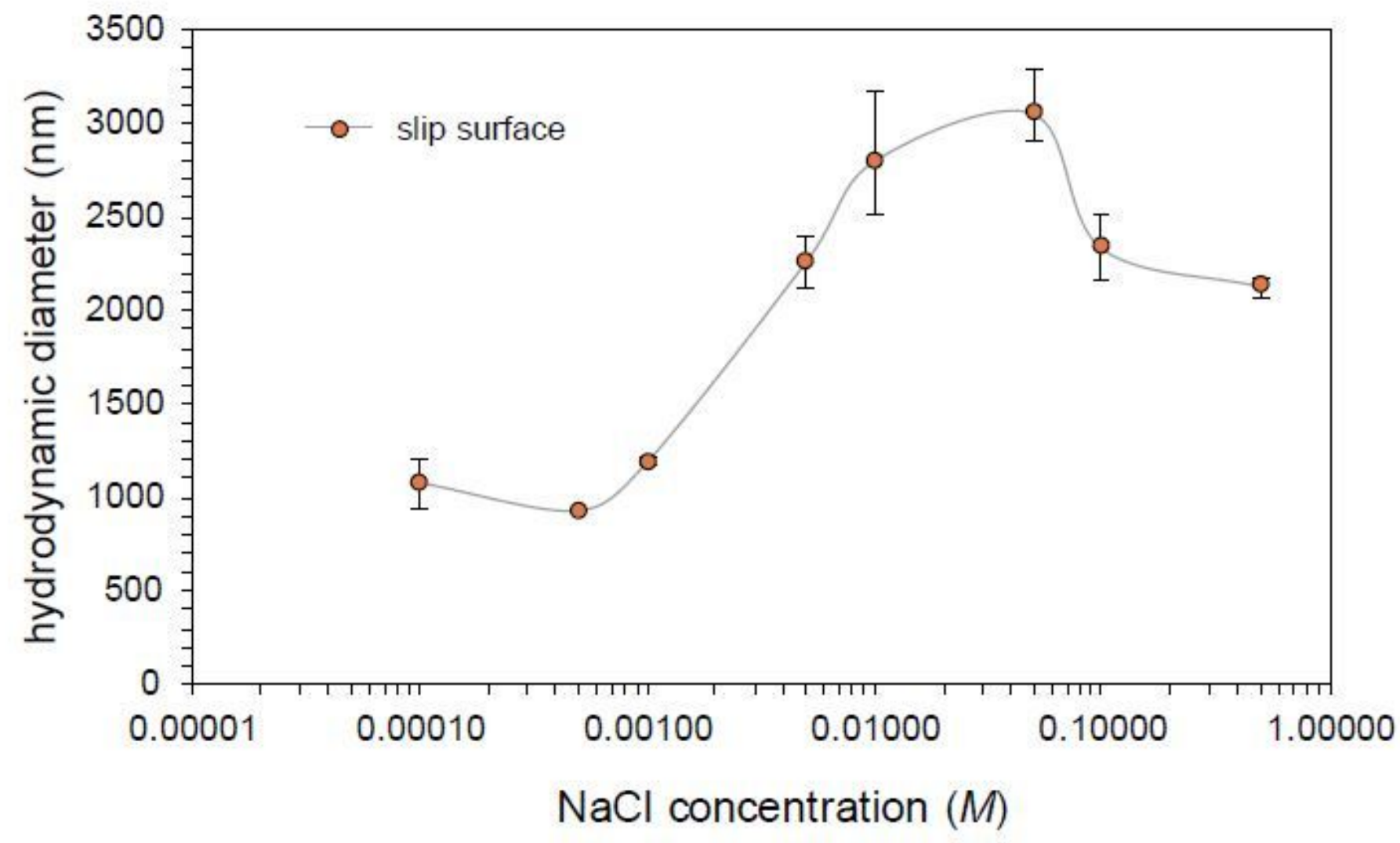

Figure 8

Hydrodynamic diameter of particles $(\mathrm{nm})$. The diameter was measured by dynamic light scattering as a function of solute concentration. Error bars denote the range of three repeated measurements. 
(a)
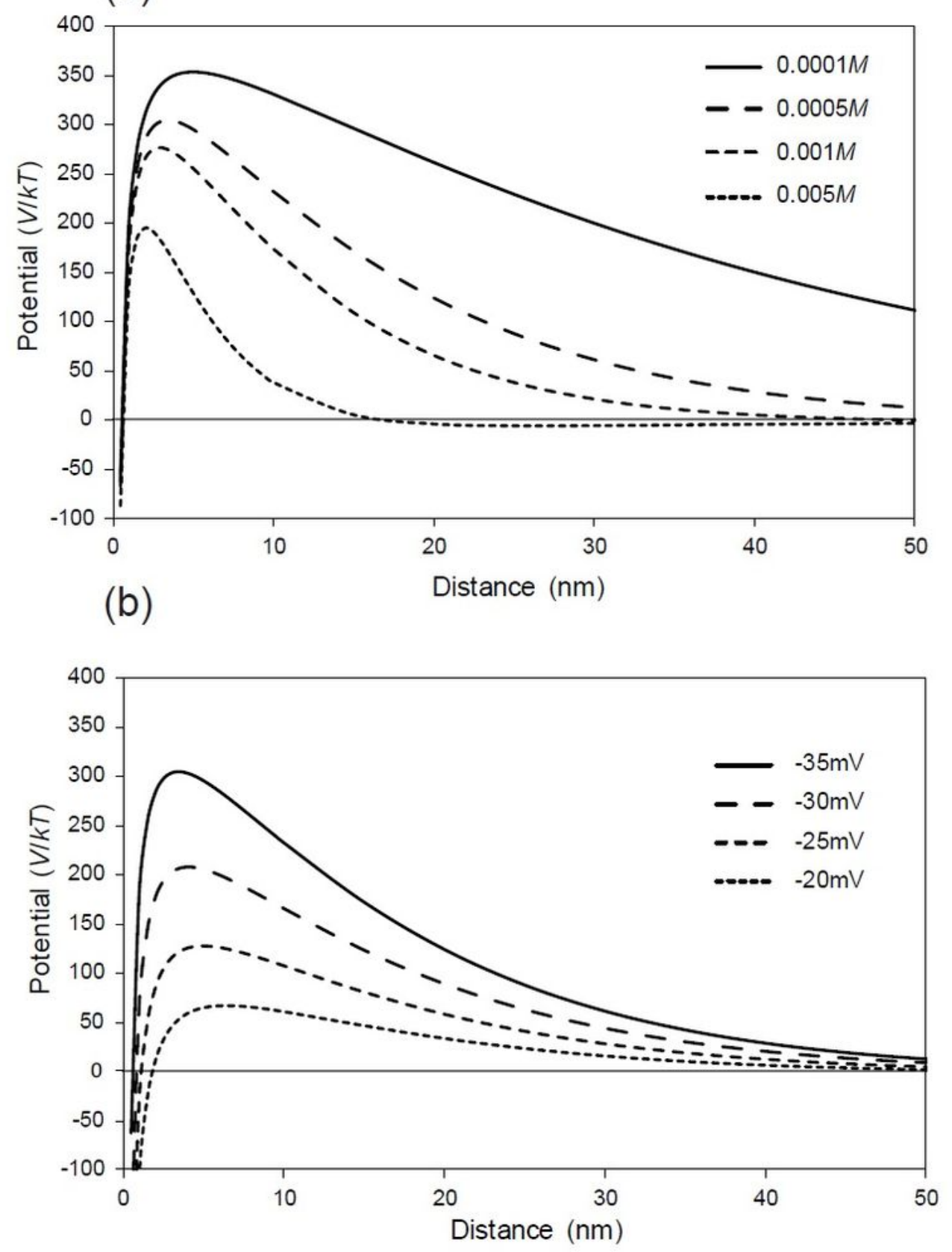

Figure 9

Interparticle potential (in kT) based on DLVO theory. (a) The zeta potential was set at $-35 \mathrm{mV}$. (b) The solute concentration was set as $5.0 \times 10-4 \mathrm{M}$.

\section{Supplementary Files}


This is a list of supplementary files associated with this preprint. Click to download.

- Table1.pdf 